\title{
CUMPRIMENTO DE SENTENÇAS INTERNACIONAIS EM MATÉRIA DE JUSTIÇA DE TRANSIÇÃO NO BRASIL
}

\author{
ENFORCEMENT OF INTERNATIONAL DECISIONS IN THE \\ FIELD OF TRANSITIONAL JUSTICE IN BRAZIL
}

\section{CUMPLIMIENTO DE SENTENCIAS INTERNACIONALES EN MATERIA DE JUSTICIA DE TRANSICIÓN EN BRASIL}

Nevitton Vieira Souza*

\begin{abstract}
1 Considerações iniciais. 2 Sentenças internacionais. 3 Cumprimento de sentenças internacionais no Brasil. 4 Condenações brasileiras em matéria de justiça de transição. 5 Considerações finais. Referências.
\end{abstract}

\section{RESUMO}

O presente artigo tem o escopo de analisar o cumprimento de sentenças internacionais em matéria de direitos humanos na ordem jurídica brasileira, com foco nas condenações impostas ao Brasil em matéria de justiça de transição pela Corte Interamericana de Direitos Humanos. $\mathrm{O}$ assunto é urgente, na medida em que o descumprimento de sentença internacional resulta em novo ilícito internacional, passível de nova responsabilização. $O$ trabalho está dividido em três partes. Na primeira, realiza-se análise sobre a sentença internacional e suas características. $\mathrm{Na}$ segunda, apresenta-se um panorama sobre as dificuldades institucionais para o cumprimento de sentenças internacionais em matéria de direitos humanos no Brasil. Na terceira parte são analisadas as medidas constantes no Caso Gomes Lund (Guerrilha do Araguaia), julgado em 2010, e no Caso Herzog, julgado em março de 2018. As conclusões finais, por sua vez, trazem ponderações sobre as insuficiências das propostas legislativas na temática. Foi empregado o método dedutivo-comparativo, a partir de fontes bibliográficas e documentais indiretas.

Palavras-chave: Sentença internacional. Justiça de transição. Corte Interamericana de Direitos Humanos. Caso Guerrilha do Araguaia. Caso Herzog.

* Doutorando em Direito Internacional e Comparado pela Faculdade de Direito da Universidade de São Paulo, USP (2018). Mestre em Direito Processual pela Universidade Federal do Espírito Santo, UFES (2015), onde graduou-se em 2013. Professor do Departamento de Direito da UFES (2015-2017). Membro do Núcleo de Estudos em Tribunais Internacionais, NETI-USP. Advogado e consultor jurídico. Faculdade de Direito da Universidade de São Paulo, São Paulo, SP, BR. E-mail: <Nevitton@usp.br>. https://orcid.org/0000-0002-2037-0434 


\begin{abstract}
The purpose of this article is to analyze the enforcement of international human rights judgments in the Brazilian legal system, focusing on the convictions imposed by the Brazilian State on transitional justice by the Inter-American Court of Human Rights. The issue is urgent, because the non-compliance with an international decision results in a new international illicit which is liable to a new accountability. The article is divided into three parts. Firstly, an analysis is made on international decisions and its characteristics. Secondly, the section overviews the institutional difficulties regarding enforcement of international human rights judgments in Brazil. The third part will analyze the determinations in the Gomes Lund (Guerrilha do Araguaia) Case, 2010 and the Herzog Case, on March 2018. The conclusion will reflect on the inadequacies of the legislative proposals in the Brazilian National Congress concerning this theme. The deductive-comparative method was used, based on indirect bibliographic and documentary sources.
\end{abstract}

Keywords: International decision. Transitional Justice. Inter-American Court of Human Rights. Guerrilha do Araguaia Case. Herzog Case.

\title{
RESUMEN
}

El presente artículo tiene como objeto el análisis del cumplimiento de sentencias internacionales en materia de derechos humanos en el orden jurídico brasileño, con foco en las condenas impuestas a Brasil en materia de justicia de transición por la Corte Interamericana de Derechos Humanos. El asunto es urgente, pues el incumplimiento de una sentencia internacional resulta en nuevo ilícito internacional, pasible de nueva responsabilización. El trabajo está dividido en tres partes. En la primera, se realiza un análisis sobre la sentencia internacional y sus características. En la segunda, se presenta un panorama sobre las dificultades institucionales para el cumplimiento de sentencias internacionales en materia de derechos humanos en Brasil. En la tercera parte se analizan las medidas constantes en el Caso Gomes Lund (Guerrilha do Araguaia), juzgado en 2010, y en el Caso Herzog, juzgado en marzo de 2018. A su vez, las conclusiones finales aportan ponderaciones sobre las insuficiencias de las propuestas legislativas en la temática. Se empleó el método deductivo-comparativo, a partir de fuentes bibliográficas y documentales indirectas.

Palabras clave: Sentencia internacional. Justicia de Transición. Corte Interamericana de Derechos Humanos. Caso Guerrilha do Araguaia. Caso Herzog.

\section{CONSIDERAÇÕES INICIAIS}

Com a nova condenação brasileira, em março de 2018, pela Corte Interamericana de Direitos Humanos, a temática da justiça de transição, inconclusa na realidade brasileira pós-Ditadura Militar (1964-1986), volta a reivindicar espaço nos fóruns jurídicos. A condenação 
no Caso Herzog, a oitava imputada ao Estado brasileiro pela Corte e a segunda na matéria - a primeira, de 2010, corresponde ao Caso Gomes Lund, conhecido como Caso "Guerrilha do Araguaia” -, enfatiza o papel da jurisdição internacional no desenvolvimento do acesso à Justiça, inclusive no âmbito interno dos Estados, face a sua força e repercussão capazes de impulsionar os mecanismos, às vezes engessados, no plano doméstico.

A observada institucionalização das relações interestatais, especialmente no pós-Segunda Guerra Mundial, acompanhada pela criação da Organização das Nações Unidas (ONU), reforçou o primado do Direito Internacional. Reforço este refletido no desenvolvimento dos mecanismos jurisdicionais de resolução de controvérsias (VARELLA, 2014), os quais visam promover a busca efetiva da paz em detrimento da utilização da força, em atenção à justiça internacional (SPAIN, 2009).

O acesso à justiça enquanto direito humano fundamental goza de reconhecido desenvolvimento normativo, jurisprudencial e doutrinário, notadamente no tocante a sua instrumentalização no direito interno, em face do Estado, e tendo este como seu garantidor principal (CAPPELLETTI; GARTH, 1988; POLIDO, 2013). Pode-se afirmar, entretanto, que a ideia de acesso à justiça internacional está permeada pela:

a) existência de um conjunto de direitos assegurados no plano internacional;

b) identificação dos titulares desses direitos oriundos de normas internacionais;

c) presença de mecanismos jurídicos disponíveis e acessíveis, nos quais se possa invocar proteção contra lesão aos direitos assegurados e;

d) exigência de efetividade às decisões judiciais emanadas dos tribunais internacionais (MENEZES, 2013).

À vista desse cenário, a presente pesquisa tem por objeto a análise do cumprimento de sentenças internacionais no Brasil, feito recorte metodológico em relação às condenações do Estado brasileiro pela Corte Interamericana de Direitos Humanos em matéria de justiça de transição. A justiça transicional pode ser compreendida como aquela associada a períodos de mudança política, como esforço no sentido de construir uma paz sustentável após período de sistemática violação de direitos humanos (VAN ZYL, 2011), mediante o enfrentamento dos crimes perpetrados por regimes opressores do passado e o fortalecimento da transição para o novo regime democrático (ARTHUR, 2009). Inicialmente marcada por respostas nacionalistas e com características locais próprias, observa-se uma aproximação da justiça de transição com o plano internacional (TEITEL, 2011), a exemplo dos mecanismos internacionais de proteção dos direitos humanos.

Os casos em que o Brasil foi condenado pela Corte IDH em decorrência de fatos ocorridos durante o período da Ditadura Militar, foram dois. O primeiro foi o Caso Guerrilha do Araguaia (2010), no qual o Estado foi condenado, dentre outras medidas, a promover a investigação, processamento e responsabilização dos agentes envolvidos no extermínio do movimento guerrilheiro e no desaparecimento forçado das vítimas, superando obstáculos formais como a prescrição e a Lei de Anistia (Lei n. 6.683/1979). O Caso Herzog e outros 
(2018) é a segunda responsabilização internacional brasileira na matéria, decorrente da tortura e assassinato do jornalista Vladmir Herzog, em 1975, praticados e acobertados por agentes estatais, até os dias atuais não identificados e responsabilizados penalmente.

Por essas razões, este artigo tecerá análise sobre as dificuldades procedimentais e institucionais enfrentadas pelas sentenças internacionais na ordem interna brasileira. Nesse propósito, inicialmente será abordada a sentença internacional no contexto de múltiplas jurisdições internacionais, para, na sequência, serem postas em evidência as dificuldades encontradas no percurso de cumprimento de sentenças internacionais em matéria de direitos humanos no Brasil. Após análise sobre as duas responsabilizações internacionais do Estado brasileiro em matéria de justiça de transição, nas conclusões serão abordadas as experiências de projetos legislativos que visam estabelecer leis-ponte no âmbito nacional. Reitera-se que foi empregado no presente trabalho o método dedutivo-comparativo, a partir de fontes bibliográficas e documentais indiretas.

\section{SENTENÇAS INTERNACIONAIS}

Duas características se destacam nas decisões dos tribunais internacionais. A primeira é sua posição no rol das fontes do Direito Internacional, constante no artigo 38 do Estatuto da Corte Internacional de Justiça e consagrada pela doutrina internacionalista (REZEK, 2014). À função integradora das decisões dos tribunais internacionais, agindo na determinação das normas jurídicas a serem aplicadas no caso concreto, é adicionada pelo exercício da jurisdição internacional a aptidão para a resolução de litígios mediante o estabelecimento de norma individual e concreta. Esta, que constitui obrigação normativa, quando ignorada, leva o sujeito à prática de novo ilícito internacional, suscetível à responsabilização (AZAR, 2003).

A coercitividade das decisões dos tribunais internacionais, sua eficácia jurídica, é tema que desperta desacordo doutrinário, opondo aqueles que enxergam na sentença internacional um grau de vinculatividade inerente ao princípio da boa-fé (MENEZES, 2013) - em decorrência dos compromissos assumidos quando da vinculação do Estado ao tratado constitutivo do tribunal internacional, bem como a sua jurisdição internacional -, àqueles que focalizam a estrutura horizontal de poder existente na esfera internacional, atrelando a efetividade da sentença internacional a considerações políticas conjunturais (WENDPAP; KOLOTELO, 2007).

$\mathrm{O}$ estudo da efetividade da sentença internacional relaciona-se com a investigação do alcance dos princípios e valores para os quais os tribunais internacionais foram criados, sua repercussão na sociedade internacional e sua contribuição para o rompimento com uma tradição bélica em direção à consagração do primado do Direito Internacional. $\mathrm{O}$ grau de desenvolvimento alcançado pelo Direito Internacional contemporâneo demanda estruturas institucionalizadas para o exercício da jurisdição internacional, a fim de garantir a prevalência da escola jurídica - firme na segurança normativa - sobre a escola diplomática - demasiada suscetível às variações políticas - na resolução das controvérsias emergentes. Assim, o cumprimento das decisões emanadas pelos tribunais internacionais reflete a efetividade de seu 
funcionamento, constituindo objeto digno de aprofundamento científico (CHARNEY, 1998).

Nesse sentido, torna-se evidente a importância que deve ser reconhecida à sentença internacional, proveniente do exercício legítimo da jurisdição internacionalmente atribuída aos tribunais internacionais. A sentença internacional é, ressalte-se, decorrência lógica e jurídica do exercício da jurisdição internacional e, portanto, deve vincular os Estados que se submeteram à jurisdição do órgão competente para proferi-la. Assim, no momento em que o Estado resolve submeter-se à jurisdição obrigatória de um tribunal internacional, ele está também resolvendo se submeter às decisões por ele emitidas. É o que decorre da expectativa de boa-fé gerada perante a sociedade internacional, bem como do dever de cumprir as obrigações internacionalmente assumidas, conforme a Convenção de Viena sobre o Direito dos Tratados (1969), notadamente seu artigo 26.

Espera-se, portanto, que diante de uma sentença internacional, os Estados envolvidos no litígio, e que tenham contra si obrigações dela decorrentes, cumpram espontaneamente o comando decisório. Ocorre que essa recente realidade de jurisdições internacionais coexistindo com jurisdições nacionais impõe aos Estados reflexões sobre suas tradicionais estruturas domésticas, de modo a pavimentar caminhos para que as estruturas institucionais internas possam dialogar e cooperar com a adequada atuação das instituições internacionais.

\section{CUMPRIMENTO DE SENTENÇAS INTERNACIONAIS NO BRASIL}

A implementação das sentenças internacionais no Brasil envolve três questões centrais (CAMPOS, 2014). A primeira é relativa à natureza das sentenças internacionais, debate que se encontra superado por hora, na medida em que a aplicação imediata de seus efeitos jurídicos no âmbito doméstico é observada, notadamente em razão do cumprimento espontâneo pelo Estado brasileiro de determinações, essencialmente pecuniárias, da Corte Interamericana de Direitos Humanos.

A segunda questão corresponde à posição que as sentenças internacionais ocupariam no ordenamento jurídico brasileiro. A doutrina entrelaça essa questão com o debate sobre a posição normativa dos tratados internacionais na ordem interna (CAMPOS, 2014). Contudo, é preciso salientar que os debates clássicos sobre a interação da ordem nacional e internacional, tendo como plano de fundo as teorias monista e dualista, podem ser superados pela visão mais atual apresentada pela teoria da transnormatividade (MENEZES, 2005).

A teoria da transnormatividade evidencia as interações entre as ordens domésticas e a internacional, demonstrando que se mostram tão fluídas no contexto social profundamente modificado pelo adensamento da globalização, que não se pode negar as influências das dinâmicas internacionais, com seus novos atores, sobre o âmbito normativo nacional. Ainda que formalmente o Estado se apresente refratário às normas internacionais, materialmente é possível identificar, desde o texto constitucional ao regulamentar, influências dos avanços normativos internacionais - sejam em matéria de proteção aos direitos humanos, sejam em matéria comercial, ambiental, contratual etc. 
Destarte, em relação ao ordenamento jurídico brasileiro - para além da posição constitucional, supralegal ou ordinária que as normas internacionais podem formalmente ocupar (BRASIL, 2009a) -, as sentenças internacionais devem gozar de status de título executivo, na medida em que houver submissão brasileira à jurisdição internacional de determinado tribunal internacional.

Conforme já se afirmou, o ato jurídico legítimo para submeter o Brasil à jurisdição internacional também o é para submetê-lo às decisões legitimamente provenientes do respectivo tribunal internacional. Tal entendimento, que ora defende-se, está em perfeita harmonia com os princípios constitucionais regentes da atuação brasileira no âmbito internacional (artigo 4, da CRFB/88) - especialmente no que se refere ao inciso VII, que assevera a solução pacífica dos conflitos. Ademais, os Atos das Disposições Constitucionais Transitórias, artigo 7º é enfático no sentido de que "o Brasil propugnará pela formação de um tribunal internacional dos direitos humanos" (BRASIL, 1988, online), confirmando a vocação constitucional brasileira para a plena inserção em jurisdições internacionais.

O Brasil, atualmente, reconhece e se submete à jurisdição internacional da Corte Internacional de Justiça (Decreto n. 19.841/1945), do Tribunal Internacional do Direito do Mar (Decreto n. 99.165/1990), do Órgão de Solução de Controvérsias da OMC (Decreto n. 1.355/1994), do Tribunal Penal Internacional (Decreto n. 4.388/2002), da Corte Interamericana de Direitos Humanos (Decreto n. 4.463/2002) e do Tribunal Permanente de Revisão do Mercosul (Decreto n. 4.982/2004).

Assim, as decisões provenientes das jurisdições internacionais as quais o Brasil se submete não dependem de atos domésticos que as internalizem, como ocorre com as decisões estrangeiras. Dito de outro modo, não há que se falar em necessidade de ato de reconhecimento formal e posterior da ordem nacional em relação à sentença internacional, pois tal ato, capaz de conferir legitimidade ao órgão internacional prolatante, deu-se no momento da submissão a sua jurisdição internacional. Desse modo, afirma-se que a sentença internacional é plenamente apta à produção de efeitos jurídicos no âmbito doméstico tão logo seja expedida.

Cumpre salientar, nessa perspectiva, que o próprio Superior Tribunal de Justiça (STJ) já teve a possibilidade de se manifestar sobre a matéria (GUERRA; MARCOS, 2018), corroborando o entendimento aqui desenvolvido. Ao analisar o pedido de homologação da Sentença Estrangeira Contestada n. 2.707, de relatoria do Min. Francisco Falcão, a Corte Especial do STJ indeferiu o pedido pois, a bem da verdade, se tratava de sentença internacional proferida pela Corte Permanente de Justiça Internacional. Após concluir que inexistia sentença estrangeira, mas uma decisão internacional proferida por um tribunal internacional, especificamente em contencioso envolvendo o Brasil e a França, a Corte Especial destacou que tal ato prescinde de qualquer tipo de exequatur ou homologação (BRASIL, 2009b). Destaque-se, ademais, que inexiste procedimento regimental no tribunal destinado às sentenças internacionais.

Ao ser tratado o tema do cumprimento de sentenças internacionais é natural a correlação intuitiva com o sistema de execução coercitiva existente no âmbito interno, na mesma 
medida em que é intuitivo estabelecer relação entre tribunais internacionais e tribunais domésticos. Apesar de compreensível, deve-se ter atenção às especificidades de cada um dos planos (GUZMAN, 2008). O sistema de execução estatal de sentenças domésticas é marcado pela estrutura coercitiva que o sustenta, a que se deve em grande medida sua efetividade. No âmbito da jurisdição internacional, entretanto, inexiste estrutura formal e legal desenhada para dar cumprimento coercitivo às decisões emanadas por tribunais internacionais (VASCONCELOS, 2016).

A terceira questão central que Campos (2014) apresenta em relação ao cumprimento de sentenças internacionais, tendo por objeto inicial as sentenças da Corte Interamericana de Direitos Humanos, faz referência à necessidade de arranjos institucionais internos. Isto porque, em que pese não seja necessário ato de internalização da sentença internacional na ordem doméstica - como acontecem com as sentenças estrangeiras, as quais demandam um ato de reconhecimento interno (SOUZA, 2018) -, sua execução imediata é dificultada pela inexistência de mecanismos específicos abstratamente delineados para tal finalidade. Principalmente quando a implementação implica em modificação ou produção de atos por parte do Legislativo ou do Judiciário (VARELLA, 2014).

Destarte, diferente do que ocorre com as sentenças estrangeiras - provenientes de outra jurisdição nacional e que se pretende que produza efeitos jurídicos na ordem doméstica -, que apresentam sistemas de reconhecimento próprios (SOUZA, 2018), constata-se que o cumprimento de decisões internacionais no Brasil não dispõe de nenhuma norma processual específica. Esse cenário se monstra ainda mais complexo quando se cogita na multiplicidade de obrigações - obrigações de dar, de fazer, de não fazer, de entregar - que as sentenças internacionais podem impor aos Estados.

O problema fica mais palpável tendo por base as condenações internacionais já existentes em relação ao Estado brasileiro, no âmbito da Corte Interamericana de Direitos Humanos. Até o momento, foram oito condenações: i) Caso Ximenes Lopes, 2006; ii) Caso Escher e outros, 2009; iii) Caso Garibaldi, 2009; iv) Caso Gomes Lund e outros (Guerrilha do Araguaia), 2010; v) Caso Trabalhadores da Fazenda Brasil Verde, 2016; vi) Caso Favela Nova Brasília, 2017; vii) Caso Povo Indígena Xucuru e seus membros, 2018; viii) Caso Herzog e outros, 2018.

As sentenças internacionais condenatórias acima mencionadas contemplam obrigações de distintas naturezas, destacando uma das principais peculiaridades das jurisprudências da Corte Interamericana de Direitos Humanos, isto é, a determinação não apenas de medidas de caráter pecuniário, mas a imputação adicional de medidas de não repetição e de satisfação, no sentido de buscar a reparação integral da violação (CALDERON GAMBOA, 2013). Essa multiplicidade de natureza das prestações determinadas enseja maior complexidade ao procedimento de cumprimento.

A reparação integral, que amplia a diversidade de ações que podem ser imputadas pela Corte Interamericana aos Estados partes, fundamenta-se no artigo 63.1 da Convenção Americana sobre Direitos Humanos (1969, online), que permite a determinação não somente de 
medidas que assegurem aos prejudicados o gozo do seus direitos ou liberdades violadas, mas também providências que visem "reparar as consequências da medida ou situação que haja configurado a violação desses direitos, bem como o pagamento de indenização justa à parte lesada."

Destarte, dentre as condenações apontadas, podem ser exemplificadas a seguintes obrigações imputadas ao Estado brasileiro:

a) continuar a desenvolver programas de formação e capacitação dos profissionais de saúde ligados à atenção à saúde mental, tendo por base os parâmetros internacionais na matéria (CORTE IDH, 2006);

b) investigar e julgar no plano interno, em prazo razoável, os responsáveis pelos atos violadores dos direitos das vítimas (CORTE IDH, 2009a; CORTE IDH, 2009b);

c) adotar medidas necessárias para tipificar o crime de desaparecimento forçado (CORTE IDH, 2010);

d) adotar medidas para afastar a prescrição do crime de redução à situação análoga à de escravo (CORTE IDH, 2016);

e) adotar medidas necessárias para que o Rio de Janeiro estabeleça metas e políticas de redução da violência policial (CORTE IDH, 2017);

f) garantir, de forma imediata e efetiva, o direito à propriedade coletiva do Povo Indígena Xucuru sobre seu território (CORTE IDH, 2018a);

g) adotar medidas para se reconhecer, sem exceção, a imprescritibilidade dos crimes contra a humanidade, segundo os parâmetros internacionais (CORTE IDH, 2018b).

Em que pese a Convenção Americana estabeleça que as decisões emanadas pela Corte devam ser cumpridas pelos Estados partes (artigo 68.1), bem como sejam sentenças definitivas e irrecorríveis (artigo 67), o texto convencional somente indicou o percurso processual para a execução da parte indenizatória da sentença condenatória internacional. De acordo com o artigo 68.2 da Convenção, a parte pecuniária da sentença poderá ser executada pelo mesmo processo de execução de sentenças contra o Estado. O que, no Brasil, equivale ao processo para execução de sentença em face da Fazenda Pública, perante a Justiça Federal, nos termos dos artigos 109, III, e 100 da Constituição de 1988; e dos artigos 910, 534 e 535 do Código de Processo Civil de 2015.

Ao analisar as determinações da Convenção Americana, Corasaniti (2009) observa que entre os artigos 63 e 68 ocorre uma "relação imperfeita", na medida em que estabelece a reparação integral e sua ampla abrangência - para além de medidas indenizatórias -, mas somente apresenta procedimento para a execução das compensações econômicas.

O que se infere da Convenção Americana é que foi deixado aos Estados a incumbência de estabelecerem os mecanismos internamente adequados para proporcionar a implementação das decisões internacionais oriundas da Corte Interamericana (CANÇADO TRINDADE, 2013). Dessa forma, em que pese o caminho indicado para a execução das condenações pecuniárias, percorrê-lo no Brasil resvalaria em ao menos dois empecilhos. O primeiro é atinente 
aos custos e à morosidade do processo de execução em face da Fazenda Pública, notadamente um obstáculo a mais para o alcance da reparação pretendida. $O$ segundo concerne ao sistema de precatórios adotado pela Constituição Federal, o qual teria a potencialidade fática de neutralizar os objetivos reparatórios do sistema de proteção.

Em vista disso, ao tratar da questão, Campos (2014) observa que, no Brasil, foram adotados arranjos institucionais a fim de dar cumprimento às decisões. Exemplo desses arranjos, verificado primeiramente no Caso José Pereira - o primeiro acordo de solução amistosa que envolveu o Brasil e a Comissão Interamericana de Direitos Humanos (CIDH, 2003) -, consistiu no encaminhamento pelo Executivo Federal de projeto de lei ao Congresso Nacional, em regime de urgência, a fim de determinar o pagamento indenizatório à vítima. Foi preciso a edição da Lei n. 10.706/2003 - cuja ementa explicita: "Autoriza a União a conceder indenização a José Pereira Ferreira" -, uma vez que não havia dotação orçamentária que autorizasse o Executivo a efetuar o pagamento de forma autônoma.

No esforço de aprimorar os mecanismos de cumprimento da parte pecuniária das sentenças internacionais por condenações em matéria de direitos humanos, a partir de 2004, na Lei Anual Orçamentária passou a ser prevista dotação orçamentária específica para tal finalidade, alocada no âmbito da Secretaria de Direitos Humanos (SDH). Observa-se, portanto, um deslocamento do cumprimento decisório, nesse caso, do Poder Judiciário para o Executivo, com vistas a facilitar a satisfação das sentenças internacionais condenatórias, ao menos em sua parte pecuniária.

Inobstante o arranjo encontrado, nem mesmo a parte pecuniária da sentença internacional restou plenamente afastada de obstáculos, uma vez que dependente de dotação em quantidade suficiente para adimplir com os comandos decisórios, bem como pelas dificuldades para habilitar sucessores de vítimas já falecidas. É o que se observa na decisão da 1a Vara Federal de Itaboraí (BRASIL, 2015), no Rio de Janeiro, datada de 02 de setembro de 2015, na qual a Juíza Federal Isabela Ferrari dá procedência à ação movida pela União Federal, em sede de jurisdição voluntária, a fim de dar cumprimento à obrigação internacional oriunda da condenação do Brasil, pela Corte Interamericana de Direitos Humanos, no caso Guerrilha do Araguaia (2010). Como os beneficiados eram herdeiros de Elena Gibertini Castiglia, mãe do desaparecido Líbero Giancarlo Castiglia, foi necessário reconhecimento judicial para que a União pudesse realizar as devidas indenizações aos sucessores da vítima.

Por outro lado, as obrigações extra pecuniárias das sentenças internacionais, notadamente as que se dirijam a atos a serem realizados pelo Legislativo e Judiciário - dever de investigar, processar e julgar; conclusão célere de processos judiciais; implementação de política legislativa, mediante criação ou revogação de normas; dentre outras -, continuam com impasses institucionais, na medida em que inexiste caminho normativo pavimentado em abstrato.

\section{CONDENAÇÕES BRASILEIRAS EM MATÉRIA DE JUSTIÇA DE TRAN- SIÇÃO}


Das oito condenações contra o Estado brasileiro oriundas do Sistema Interamericano de Direitos Humanos, duas são relativas a fatos ocorridos durante o período da Ditadura Militar no Brasil (1964-1985). São o Caso Gomes Lund e outros, conhecido como "Guerrilha do Araguaia”, julgado em 2010, e o Caso Herzog e outros, julgado em março de 2018.

O Caso Guerrilha do Araguaia consiste em marco histórico nacional em matéria de justiça de transição, posto ser a primeira responsabilização imposta ao Brasil pelas violações sistemáticas de direitos humanos perpetradas por agentes estatais durante a Ditadura Militar. Dentre as violações imputadas estão as contra o artigo 1 (obrigação de respeitar os direitos), artigo 2 (dever de adotar disposições de direito interno), artigo 3 (direito ao reconhecimento da personalidade jurídica), artigo 5 (direito à integridade pessoal), artigo 7 (direito à liberdade pessoal), artigo 8 (garantias judiciais), artigo 9 (princípio da legalidade e da retroatividade), artigo 13 (liberdade de pensamento e de expressão), artigo 25 (proteção judicial) - todos da Convenção Americana de Direitos Humanos (1969).

A questão de fundo trata do movimento de resistência chamado de Guerrilha do Araguaia, ocorrido no início da década de 1970, na divisa entre os estados do Tocantins e Pará. A reação militar foi no sentido de exterminar toda a guerrilha, de modo que nos fins de 1974 já não havia resistência na região. Inicialmente, o Estado encobriu os acontecimentos, assim como promoveu o desaparecimento forçado dos integrantes da guerrilha. Posteriormente, após pressões, o Brasil reconheceu a ocorrência do extermínio, motivo pelo qual foi aberta ação perante a Justiça Federal no Distrito Federal, em 1982, a fim de recuperar as informações sobre o destino das vítimas. Em razão dos inúmeros percalços processuais e administrativos enfrentados, bem como pela impossibilidade de responsabilização dos agentes, em atenção à lei de anistia em vigor, o caso foi levado à Corte Interamericana de Direitos Humanos.

Em sua decisão, a Corte reconhece o caráter continuado ou permanente dos fatos constitutivos do desaparecimento forçado, motivo pelo qual confirma sua competência sobre os fatos, embora ocorridos antes de 10 de dezembro de 1998, data em que o Brasil reconheceu a competência contenciosa da Corte IDH ${ }^{1}$. Como o Estado já havia reconhecido sua responsabilidade internacional sobre os fatos ${ }^{2}$, a Corte passou a se pronunciar sobre a incompatibilidade da Lei de Anistia com a Convenção Americana e sobre a liberdade de acesso à informação.

Conclui a Corte IDH que a Lei de Anistia (Lei n. 683/1979) não é compatível com as normas da Convenção Americana de Direitos Humanos, ratificada pelo Brasil (Decreto n.

1 Cumpre lembrar que embora a promulgação da Declaração de Reconhecimento da Competência Obrigatória da Corte Interamericana de Direitos Humanos pelo Estado brasileiro tenha ocorrido em 2002, por meio do Decreto n. 4.463, este reconhece a jurisdição contenciosa da Corte em relação aos fatos posteriores a 10 de dezembro de 1998, data do depósito da Declaração junto à Secretaria-Geral da Organização dos Estados Americanos.

2 Notadamente em virtude da Lei n. 9.140, de 4 de dezembro de 1995, cujo artigo 1º dispõe: "São reconhecidos como mortas, para todos os efeitos legais, as pessoas que tenham participado, ou tenham sido acusadas de participação, em atividades políticas, no período de 2 de setembro de 1961 a 5 de outubro de 1988, e que, por este motivo, tenham sido detidas por agentes públicos, achando-se, deste então, desaparecidas, sem que delas haja notícias." (BRASIL, 1995, online). 
678/1962), pois seu objetivo é tornar impune as graves violações a direitos internacionais cometidos durante a Ditadura Militar, indo de encontro aos direitos estabelecidos pela Convenção Americana no que se refere ao acesso à justiça, às garantias e proteções judiciais, bem como ao dever dos Estados de combater, investigar e punir tais violações.

Diante do quadro encontrado, a condenação da Corte ao Estado brasileiro pode ser apresentada nos seguintes termos: i) dever de conduzir de forma eficaz, perante a jurisdição ordinária, a investigação penal dos fatos, a fim de esclarecê-los, determinar as correspondentes responsabilidades penais e aplicar efetivamente as sanções e consequências que a lei preveja; ii) dever de realizar todos os esforços para determinar o paradeiro das vítimas desaparecidas, identificar e entregar os restos mortais a seus familiares, com a maior brevidade e sem custos; ii) dever de oferecer tratamento médico e psicológico que requeiram as vítimas; iv) dever de realizar as publicações determinadas na decisão; v) dever de realizar um ato público de reconhecimento de responsabilidade internacional a respeito dos fatos; vi) dever de implementar, em um prazo razoável, um programa ou curso permanente e obrigatório de capacitação e formação sobre direitos humanos, dirigido aos membros das Forças Armadas; vii) dever de adotar medidas que sejam necessárias para tipificar, em prazo razoável, o delito de desaparecimento forçado de pessoas, em conformidade com os standards interamericanos, e adotar ações para garantir o efetivo julgamento e a punição em relação aos fatos constitutivos de desaparecimento forçado através dos mecanismos existentes no direito interno; viii) dever de continuar as iniciativas de busca, sistematização e publicação de toda informação sobre a Guerrilha do Araguaia, assim como da informação relativa a violações de direitos humanos ocorridas durante o regime militar, garantindo o acesso livre; ix) dever de pagar as quantias fixadas a título de indenização por danos materiais e imateriais, bem como custas processuais.

A segunda condenação em matéria de justiça de transição contra o Brasil, proveniente da Corte IDH, ocorreu em março de 2018, no Caso Herzog e outros. O contexto fático se tornou amplamente conhecido pela foto emblemática do suicídio forjado do jornalista Vladmir Herzog, vítima de tortura e assassinato por agentes do Estado brasileiro durante a Ditadura Militar, em 25 de outubro de 1975. Em que pese o Estado tenha assumido responsabilidade pelas mortes no período, dentre as quais a de Herzog, assim como os relatórios da Comissão Especial de Mortos e Desaparecidos Políticos, publicado em 2007, e da Comissão Nacional da Verdade, publicado em 2014, tenham concluído pela submissão de Herzog à tortura e assassinato, os familiares da vítima não conseguiram sucesso nas incursões penais, que foram obstruídas em razão da Lei de Anistia, prescrição e inexistência de tipificação interna de crimes contra a humanidade.

A Corte concluiu que o Estado brasileiro é internacionalmente responsável, à luz das disposições da Convenção Americana e da Convenção Interamericana para Prevenir e Punir a Tortura (Decreto n. 98.386/1989), em relação: i) à falta de investigação, julgamento e eventual punição dos responsáveis pela tortura e assassinato de Vladmir Herzog; ii) à violação do direito à verdade, pois o Estado divulgou versão falsa da morte de Herzog e se negou a 
permitir acesso a documentos oficiais que possibilitariam a identificação dos responsáveis; iii) à violação do direito de integridade pessoal dos familiares de Herzog, tendo em vista a ausência de investigação e responsabilização.

Especificamente no tocante ao dever do Estado de investigar, processar e julgar os responsáveis por violações de direitos humanos, a Corte IDH reforçou que, conforme sua jurisprudência, o Estado não pode invocar, com a finalidade de esquivar-se de sua obrigação: i) prescrição; ii) princípio ne bis in idem; iii) leis de anistia; iv) coisa julgada e v) qualquer outra disposição análoga ou excludente similar de responsabilidade.

Nesse sentido, a Corte ordenou as seguintes reparações por parte do Estado brasileiro: i) retomar, com a devida diligência, as investigações e o processo penal que visa responsabilizar penalmente os responsáveis pela tortura e assassinato de Vladmir Herzog; ii) adotar as medidas necessárias para reconhecer, sem exceção, a imprescritibilidade dos crimes contra a humanidade e internacionais; iii) realizar um ato público de reconhecimento de responsabilidade internacional pelos crimes cometidos contra Herzog, como desagravo à memória da vítima; iv) publicar a sentença em sua integridade; v) pagar as quantias fixadas a título de indenizações por danos materiais e imateriais, bem como as custas.

Como pode ser observado, as condenações da Corte Interamericana de Direitos Humanos vão além do simples reconhecimento da responsabilização internacional do Estado e prescrição de indenizações a serem por ele arcadas. A Corte vai além, com vistas a alcançar o que entende por reparação integral (CALDERON GAMBOA, 2013), conferindo proteção adequada às vítimas, diretas e indiretas dos casos sub judice, assim como adotando medidas para prevenir a reincidência nas violações de direitos humanos, chamadas de medidas de não-repetição. A natureza múltipla das prestações determinadas pelas decisões da Corte torna mais complexo os modos de implementação, exigindo dos Estados maior interação entre os Poderes constituídos e os distintos níveis da organização política interna.

É possível sistematizar os itens das condenações acima apresentados conforme o Poder constituído competente para cumpri-los, ressaltando que alguns deles precisam da atuação conjunta. Nas competências do Executivo recaem maior parte das determinações, dentre as quais (i) empreender investigações com vistas a determinar o paradeiro das vítimas (Caso Araguaia) e os responsáveis pelas práticas de tortura, assassinato e desaparecimento forçado (ambos os casos); (ii) dar publicidade as sentenças internacionais e demais informações levantadas pelas investigações; (iii) realizar ato público de reconhecimento de responsabilidade internacional; (iv) oferecer tratamento médico e psicológico às vítimas; (v) implementar programa de aperfeiçoamento e capacitação em direitos humanos de todo o pessoal das Forças Armadas; (vi) pagar as indenizações fixadas em benefício das vítimas, bem como as custas. Embora o Executivo possa dar cumprimento às determinações expostas, aquelas que dependem de dotação orçamentária precisam de participação do Legislativo, na aprovação da inclusão.

No bojo das competências do Legislativo, ainda que com as participações constitucionalmente previstas para o Executivo no processo legislativo, estão as determinações que 
visam a tipificação do delito de desaparecimento forçado de pessoas, em conformidade com os parâmetros interamericanos, e a previsão normativa da imprescritibilidade, sem exceção, dos crimes contra a humanidade e crimes internacionais. Ao sabor das variações de interesses políticos, o Congresso Nacional vivencia dificuldades em implementar as medidas de não-repetição de violações de direitos humanos, por meio da adoção de instrumento normativo. É o que pode ser verificado pelo andamento de tramitações do Projeto de Lei n. 301/2007 (Apensado Projeto de Lei n. 4.038/2008), na Câmara dos Deputados, que trata sobre a tipificação sobre os crimes de competência do Tribunal Penal Internacional, dentre os quais os crimes contra a humanidade, sendo o artigo 30 sobre o desaparecimento forçado. Conforme Jardim (2011), faz-se necessário, ainda, que o projeto seja adaptado à jurisprudência da Corte IDH, a fim de afastar, por exemplo, as competências da Justiça Militar persistentes no projeto.

Em relação às competências do Judiciário, as persecuções penais, a fim de que sejam apuradas as responsabilizações individualizadas dos agentes que perpetraram as violações de direitos humanos, bem como a consequente condenação, são cruciais para a implementação das sentenças internacionais que condenaram o Estado brasileiro. A Corte ressalta, em ambas as sentenças, a importância do controle de convencionalidade (MAC-GREGOR, 2017), cumprindo essencialmente, mas não exclusivamente, ao Judiciário prezar pela observância das normas internacionais protetoras dos direitos humanos. Nesse mister, uma aproximação dos magistrados nacionais com a jurisprudência da Corte IDH, em um diálogo jurisdicional (PIOVESAN, 2014), contribui para a concretização de todo sistema protetivo no âmbito interno.

A Corte destacou a incompatibilidade de subterfúgios que visem impedir a apuração de fatos violadores de direitos humanos, dentre os quais a prescrição e a Lei de Anistia, frequentemente utilizados pelo Judiciário nacional para fundamentar decisões denegatórias de acesso à investigação penal, responsabilização dos agentes estatais e reparação às vítimas e suas famílias - como apontam os contextos fáticos dos Casos Guerrilha do Araguaia e Herzog.

No que tange à Lei de Anistia, tanto o Judiciário como o Legislativo podem enfrentar e superar seus efeitos de impedir o acesso das vítimas à Justiça. A Corte reitera sua jurisprudência no sentido de entender ineficaz a Lei de Anistia, pois contrária às garantias de acesso à Justiça e às garantias processuais contidas na Declaração Americana, bem como aos deveres de investigação e responsabilização imputados por ela aos Estados parte. São feitas referências expressas ao julgamento, pelo Supremo Tribunal Federal, em 2010, da Ação de Descumprimento de Preceito Fundamental (ADPF) n. 153, quando, por sete votos a dois, rejeitou pedido de revisão da Lei de Anistia, declarando-a compatível com a Constituição Federal de 1988. Seu efeito vinculante recai sobre todos os órgãos da Administração e do Judiciário.

A posição do STF ignora completamente a forte jurisprudência da Corte IDH, assim como o fato de ser esta o órgão competente para determinar o conteúdo e o alcance das normas contidas na Convenção Americana de Direitos Humanos (artigo 62), a qual o Brasil encontra-se devidamente vinculado. No julgamento da ADPF n. 153, o Supremo afirmou ter sido a Lei de Anistia o "preço pago" por uma transição democrática mais célere, acorda- 
da por representantes que possuíam legitimidade social e política no contexto histórico da época (GUERRA; MONTEIRO, 2018). Ao entenderem que a anistia foi ampla, alcançando tanto os atos criminais dos agentes do regime de opressão como os da resistência, sopesam de maneira inapropriada o flagrante desequilíbrio de força entre ambos. Ademais, ignoram a natureza internacional das violações, que redundam em responsabilização internacional do Estado brasileiro, que não podem ser afastadas por atos domésticos, sejam legislativos (Lei de Anistia), sejam jurisdicionais (ADPF).

Uma outra possibilidade, ainda, é juridicamente possível, assim como conta com exemplo na Argentina (PERRONE-MOISÉS, 2012). Trata-se da revogação da Lei de Anistia pelo Legislativo. Apesar de tal via encontrar compatibilidade com a ratio da ADPF n. 153, traria consigo apenas efeitos ex nunc, preservando a produção dos efeitos pelos primeiros 30 anos da Constituição Cidadã. Por essa razão, decisão do STF reconhecendo a não recepção da Lei de Anistia pela ordem constitucional vigente, por ter efeitos ex tunc, portanto, mais amplos, se amolda melhor à jurisprudência da Corte IDH.

Voltando ao âmbito do Judiciário, um outro exemplo regional que poderia ser seguido pela Supremo Tribunal Federal, a fim de mitigar as responsabilizações internacionais decorrentes do descumprimento das decisões da Corte IDH, é o adotado pelo Corte Suprema chilena. A Corte Suprema do Chile desde 1998, no julgamento histórico do Caso Pedro Poblete Córdova, adequou seu entendimento em relação à Ley de Amnistía (Decreto Lei n. 2.191/1978), referente aos crimes do período militar chileno, afastando do âmbito de aplicação da lei os crimes de desaparecimento forçado, considerados crimes permanentes e contínuos até que os corpos sejam localizados (AGUILAR, 2013; COLLINS, 2013). Desse modo, encampando a jurisprudência da Corte Interamericana de Direitos Humanos, foi permitido que inúmeras vítimas reabrissem processos perante os órgãos jurisdicionais nacionais em busca de seus familiares ainda não localizados (SIKKINK, 2008).

\section{CONSIDERAÇÕES FINAIS}

A ausência de mecanismos próprios voltados à implementação mais célere de sentenças internacionais no ordenamento interno brasileiro é notada há tempos pela doutrina (PIOVESAN, 2014). Também o Congresso Nacional brasileiro já observou a tramitação de projetos de leis com essa finalidade - Projeto de Lei n. 3.214/2000, Projeto de Lei n. 4.667/2004 e Projeto de Lei do Senado n. 220/2016. Tais esforços legislativos visam alcançar as chamadas "leis-ponte" ou "leis de implementação", que são instrumentos normativos que estabelecem procedimentos em abstrato para a implementação, no âmbito doméstico, das sentenças emanadas de tribunais internacionais.

Todas as tentativas legislativas até agora empreendidas no Congresso foram restritivas, somente versando sobre as sentenças internacionais em matéria de direitos humanos e o cumprimento da parte pecuniária das ditas sentenças, estabelecendo procedimentos de execução e direito de regresso. O PLS n. 220/2016 é o maior dentre as propostas até aqui apresentadas, 
bem como apresenta maiores impactos sobre a implementação das decisões internacionais em matéria de direitos humanos. Explicita a obrigatoriedade e a produção automática de efeitos, o dever de ser observada por todos os Poderes da União, dos Estados, do Distrito Federal e dos Municípios, assim como pelo Ministério Público. Reforça a desnecessidade de procedimento homologatório. Afasta obstáculos como a prescrição, decadência, coisa julgada, anistia ou outros semelhantes, devendo ser as sentenças internacionais em matéria de direitos humanos cumpridas com prioridade. Prevê, ainda, a dotação orçamentária destinada especificamente para o cumprimento das sentenças internacionais.

Apesar de o PLS n. 220/2016 versar pontualmente sobre as obrigações não pecuniárias decorrentes dos comandos decisórios internacionais, ao inserir textualmente as decisões internacionais em matéria de direitos humanos no rol dos títulos executivos judiciais, ainda perde a oportunidade de estruturar ações institucionais coordenadas entre os Poderes Constituídos e entre os Entes Federados, com vistas a satisfazer as obrigações internacionais.

Numa perspectiva latino-americana, verifica-se que países como a Colômbia (Lei n. 188/1996), Costa Rica (Convênio Sede entre o Governo da República da Costa Rica e a Corte Interamericana de Direitos Humanos, 1981) e Peru (Lei n. 23.506/1982) já possuem normas ou leis especificas (leis-ponte) que versam sobre a implementação doméstica de decisões internacionais em matéria de direitos humanos. Dentre elas, a mais expressiva, ao mesmo tempo pontual, é a da Costa Rica, pois a referida norma está inserida no Convênio Sede estabelecido entre o Estado e a Corte IDH. Por meio deste tratado internacional, as sentenças da Corte são equivalentes às sentenças do Estado costarriquenho.

Conforme visto, as sentenças da Corte Interamericana de Direitos Humanos têm o escopo de conferir proteção integral às vítimas, por vezes estabelecendo medidas de não-repetição que demandam a coordenação entre as diferentes Funções do Poder para sua adequada implementação. Em que pese seja competência da Presidência da República conduzir a política internacional, representando o Estado externamente, sabe-se que a responsabilização internacional decorrente de ato ilícito internacional alcança o Estado de forma integral (CRAWFORD, 2003), incluindo todos os Poderes Constituídos e os distintos níveis de organização política. Destarte, o descumprimento de imputações relativas ao Legislativo e Judiciário também podem inserir o Estado em situação de nova responsabilização internacional - uma vez que o descumprimento de sentença internacional constitui nova violação.

Cabe reiterar, nesse sentir, que o Estado não pode alegar razões de direito interno para justificar o inadimplemento de obrigações internacionais - conforme disposto na Convenção de Viena sobre o Direito dos Tratados (1969). Destarte, as dificuldades institucionais advindas da ausência de coordenação entre os Poderes Constituídos ou entre os Entes Federados, bem como a inexistência de esforços envidados no sentido de mitigá-las ou superá-las, não se mostram juridicamente capazes de impedir a situação de nova responsabilização do Estado por descumprimento da sentença internacional.

Essa noção escapa, aparentemente, da preocupação dos agentes públicos detentores 
de mandatos no Legislativo e de cargos no Judiciário, uma vez que os comandos decisórios internacionais destinados à modificação ou prática de atos de competência dessas funções do Poder encontram maiores obstáculos. A reabertura de processos visando a responsabilização de agentes perpetradores de graves violações de direitos humanos durante o período da Ditadura Militar frequentemente encontra obstáculos em magistrados cujas decisões demonstram demasiado apego a formalidades processuais internas do que a garantias de direitos humanos estabelecidas internacionalmente, ignorando que seus atos consistem em ato ilícito da República Federativa do Brasil na esfera internacional. Mais gravosa, ainda, a posição da Suprema Corte brasileira, ao persistir na manutenção dos efeitos da Lei de Anistia, indo de encontro à jurisprudência consolidada da Corte IDH sobre a inconvencionalidade de leis dessa estirpe.

Destarte, como espelho da exigência de materialidade do direito ao acesso à justiça no plano internacional (CANÇADO TRINDADE, 2008), tem-se como imperioso o cumprimento efetivo das decisões oriundas de tribunais internacionais, notadamente as provenientes de sistemas de proteção dos direitos humanos, como a Corte Interamericana. No que se refere à justiça de transição, cujo caminhar na ordem doméstica brasileira é lento quando comparado a outras experiências vizinhas, as pressões provenientes de órgãos jurisdicionais internacionais são capazes de impulsionar avanços internos (RAMANZINI; MIRANDA, 2018). Para além dos efeitos jurídicos próprios da sentença internacional, as condenações instrumentalizam movimentos sociais e institucionais que lutam pela superação de feridas históricas que, apesar de ignoradas por parcela das autoridades, continuam a provocar mazelas à jovem democracia brasileira.

\section{REFERENCIAS}

AGUILAR, Paloma. Jueces, Repression y Justicia Transicional en España, Chile y Argentina. Revista Internacional de Sociologia - RIS, Córdoba, Espanha, v. 71, n. 2, p. 281-308, maio/ago. 2013.

ARTHUR, Paige. How transitions reshaped human rights: a conceptual history of transitional justice. Human Rights Quarterly, Cincinnati, OH, USA, v. 31, n. 2, p. 321-367, maio 2009.

AZAR, Aïda. L'exécution des décisions de la Cour internationale de justice. Bruxelas: Bruylant: Ed. de l'Université de Bruxelles, 2003.

BRASIL. Lei $\mathbf{n}^{\circ}$ 9.140, de 04 de dezembro de 1995. Reconhece como mortas pessoas desaparecidas em razão de participação, ou acusação de participação, em atividades políticas, no período de 2 de setembro de 1961 a 15 de agosto de 1979, e dá outras providências. Brasília, DF: Presidência da República, 1995. Disponível em: http://www.planalto.gov.br/ccivil_03/ LEIS/L9140.htm. Acesso em: 10 ago. 2019.

BRASIL. [Constituição (1988)]. Constituição da República Federativa do Brasil de 
1988. Brasília, DF: Presidência da República, 1988. Disponível em: http://www.planalto. gov.br/ccivil_03/Constituicao/Constituiçao.htm. Acesso em: 10 ago.

BRASIL. Supremo Tribunal Federal (Tribunal Pleno). Recurso Extraordinário (RE) n. 466.343-SP. Ementa: Prisão civil. Depósito. Depositário infiel. Alienação fiduciária. Decretação da medida coercitiva. Inadmissibilidade absoluta [...]. Relator: Min. Cezar Peluso. Data de Julgamento: 03 dez. 2008. Data de Publicação: 05 jun. 2009a. Disponível em: https://portal.stf.jus.br/jurisprudencia/. Acesso em: 10 ago. 2019.

BRASIL. Superior Tribunal de Justiça (Corte Especial). Sentença Estrangeira Contestada (SEC) n. 2.707-NL. Ementa: Sentença estrangeira. Decisão proferida pela Corte Permanente de Justiça Internacional de Haia, em 1929, tendo como partes o Governo brasileiro e o Governo francês. Ilegitimidade de empresa estranha à decisão para postular a sua homologação. Ademais, decisão que não se subsume ao conceito de sentença estrangeira e cuja homologação afrontaria a soberania nacional. Relator: Min. Francisco Falcão. Data de Julgamento: 03 dez. 2008. Data de Publicação: 19 fev. 2009b. Disponível em: https://scon. stj.jus.br/SCON/. Acesso em: 10 ago. 2019.

BRASIL. Ministério Público Federal. Grupo de Trabalho Justiça de Transição: atividades de persecução penal desenvolvidas pelo Ministério Público Federal. 2. Câmara de Coordenação e Revisão. Coordenação e organização de Raquel Elias Ferreira Dodge, Subprocuradora-Geral da República. Brasília: MPF/2.CCR, 2014. 262 p. Disponível em: http:// www.mpf.mp.br/atuacao-tematica/ccr2/coordenacao/comissoes-e-grupos-de-trabalho/ justica-transicao/relatorios-1/Relatorio\%20Justica\%20de\%20Transicao\%20-\%20Novo. pdf/view. Acesso em: 10 ago. 2019.

BRASIL. Tribunal Federal Regional (2. Região). Procedimento de Jurisdição Voluntária n. 0183301-69.2014.4.02.5107. Ementa: Trata-se de procedimento de jurisdição voluntária proposto pela União Federal, no qual se objetiva o cumprimento de obrigação internacional, oriunda da condenação do Estado brasileiro, pela Corte Interamericana de Direitos Humanos, ao pagamento de verbas indenizatórias às vítimas [...]. Seção Judiciária do Rio de Janeiro. 1a Vara Federal de Itaboraí. Juíza Federal Isabela Ferrari. Data de Julgamento: 02 set. 2015. Data de Publicação: 10 set. 2015. Disponível em: https://www10.trf2.jus.br/ consultas/jurisprudencia/. Acesso em: 10 ago. 2019.

CALDERÓN GAMBOA, Jorge F. La reparación integral em la jurisprudencia de la Corte Interamericana de Derechos Humanos: estândares aplicables al nuevo paradigma mexicano. Ciudad de México: Instituto de Investigaciones Jurídicas de la UNAM, 2013.

CAMPOS, Bárbara Pincowsca Cardoso. A trajetória da implementação de sentenças da Corte Interamericana de Direitos Humanos no Brasil. Revista do Instituto Brasileiro de Direitos Humanos, Fortaleza, v. 14, n. 14, 2014. 
CANÇADO TRINDADE, Antonio Augusto. Compliance with Judgments and Decisions: The Experience of the Inter-American Court of Human Rights: a Reassessment. Revista do Instituto Brasileiro de Direitos Humanos, Fortaleza, v. 13, n. 13, p. 29-36, 2013.

CANÇADO TRINDADE, Antônio Augusto. El derecho de acceso a la justicia em su amplia dimension. Santiago: Librotecnia, 2008.

CAPPELLETTI, Mauro; GARTH, Bryant. Acesso à justiça. Porto Alegre: Fabris, 1988.

CHARNEY, Jonathan I. Is international law threatened by multiple international tribunals? Recueil des Cours, Academie de Droit International de la Haye, v. 271, p. 101-382, 1998.

\section{CIDH (COMISSÃO INTERAMERICANA DE DIREITOS HUMANOS). Convenção} Americana sobre Direitos Humanos. Assinada na Conferência Especializada Interamericana sobre Direitos Humanos, San José, Costa Rica, em 22 de novembro de 1969. Disponível em: https://www.cidh.oas.org/basicos/portugues/c.convencao_americana.htm. Acesso em: 10 ago. 2019.

CIDH (COMISSÃO INTERAMERICANA DE DIREITOS HUMANOS). Solução Amistosa no Caso José Pereira Vs. Brasil (Caso n. 11.289). Relatório n. 95, de 24 de outubro de 2003. Disponível em: https://cidh.oas.org/annualrep/2003port/Brasil.11289.htm. Acesso em: 10 ago. 2019.

COLLINS, Cath. Chile a más de dos décadas de justicia de transición. Revista de Ciencia Política, Santiago, Chile, v. 51, n. 2, p. 79-113, 2013.

CORASANITI, Vittorio. Implementación de las sentencias y resoluciones de la Corte Interamericana de Derechos Humanos: un debate necessário. Revista IIDH - Instituto Interamericano de Derechos Humanos, San José da Costa Rica, v. 49, 2009.

CORTE IDH (CORTE INTERAMERICANA DE DIREITOS HUMANOS). Caso Ximenes Lopes Vs. Brasil. Sentença. Série C. N. 149. 4 jul. 2006. Disponível em: http://www. corteidh.or.cr/docs/casos/articulos/Seriec_149_esp.pdf. Acesso em: 10 ago. 2019.

CORTE IDH (CORTE INTERAMERICANA DE DIREITOS HUMANOS). Caso Gomes Lund e outros (Guerrilha do Araguaia) Vs. Brasil. Exceções Preliminares, Mérito, Reparações e Custas. Sentença. Série C, N. 219. 24 nov. 2010. Disponível em: http://www. corteidh.or.cr/docs/casos/articulos/seriec_219_esp.pdf. Acesso em: 10 ago. 2019.

CORTE IDH (CORTE INTERAMERICANA DE DIREITOS HUMANOS). Caso Escher e outros Vs. Brasil. Exceções Preliminares, Mérito, Reparações e Custas. Sentença. Série C, N. 200. 6 jul. 2009a. Disponível em: http://www.corteidh.or.cr/docs/casos/articulos/ seriec_200_esp1.pdf. Acesso em: 10 ago. 2019. 
CORTE IDH (CORTE INTERAMERICANA DE DIREITOS HUMANOS). Caso Garibaldi Vs. Brasil. Exceções Preliminares, Mérito, Reparações e Custas. Sentença. Série C, N. 203. 23 set. 2009b. Disponível em: http://www.corteidh.or.cr/docs/casos/articulos/ seriec_203_esp.pdf. Acesso em: 10 ago. 2019.

CORTE IDH (CORTE INTERAMERICANA DE DIREITOS HUMANOS). Caso Trabalhadores da Fazenda Brasil Verde Vs. Brasil. Exceções Preliminares, Mérito, Reparações e Custas. Série C, N. 318. Sentença. 20 out. 2016. Disponível em: http://www.corteidh. or.cr/docs/casos/articulos/seriec_337_esp.pdf. Acesso em: 10 ago. 2019.

CORTE IDH (CORTE INTERAMERICANA DE DIREITOS HUMANOS). Caso Favela Nova Brasília Vs. Brasil. Exceções Preliminares, Mérito, Reparações e Custas. Série C, N. 333. Sentença. 16 fev. 2017. Disponível em: http://www.corteidh.or.cr/docs/casos/articulos/seriec_333_esp.pdf. Acesso em: 10 ago. 2019.

CORTE IDH (CORTE INTERAMERICANA DE DIREITOS HUMANOS). Caso Povo Indígena Xucuru e seus membros Vs. Brasil. Exceções Preliminares, Mérito, Reparações e Custas. Série C, N. 346. Sentença. 5 fev. 2018a. Disponível em: http://www.corteidh. or.cr/docs/casos/articulos/seriec_346_esp.pdf. Acesso em: 10 ago. 2019.

CORTE IDH (CORTE INTERAMERICANA DE DIREITOS HUMANOS). Caso Herzog e outros Vs. Brasil. Exceções Preliminares, Mérito, Reparações e Custas. Sentença. Série C, N. 353. 15 mar. 2018b. Disponível em: http://www.corteidh.or.cr/docs/casos/ articulos/seriec_353_por.pdf. Acesso em: 10 ago. 2019.

CRAWFORD, James. The International Law Commission's Articles on State Responsibility: introduction, text and commentaries. New York: Cambridge University Press, 2003.

GUERRA, Gustavo Rabay; MARCOS, Henrique J. Bezerra. O drible continental: a margem de apreciação nacional na decisão de convencionalidade do crime de desacato pelo Superior Tribunal de Justiça. Revista da Faculdade de Direito - UFPR, Curitiba, v. 63, n. 2, maio/ago. 2018.

GUERRA, Sidney C. S.; MONTEIRO, Millena. Controle de convencionalidade e o tratamento dado aos crimes ditatoriais no Brasil: reflexões acerca do posicionamento do Supremo Tribunal Federal e do entendimento da Corte Interamericana de Direitos Humanos (OEA). Revista de Direito da UNIGRANRIO, Rio de Janeiro, v. 8, p. 1-23, 2018.

GUZMAN, Andrew T. International Tribunals: A Rational Choice Analysis. Berkeley Law Scholarship Repository, University of Pennsylvania, Law Review, n. 157, p. 171-235, 2008. JARDIM, Tarciso Dal Maso. Brasil condenado a legislar pela Corte Interamericana de Direitos Humanos: da obrigação de tipificar o crime de desaparecimento forçado de pes- 
soas. Brasília: Centro de Estudos da Consultoria do Senado, 2011. Disponível em: http:// www2.senado.leg.br/bdsf/bitstream/handle/id/195270/Texto83.pdf?sequence=3. Acesso em: 10 ago. 2019.

MAC-GREGOR, Eduardo Ferrer. The Conventionality Control as a Core Mechanism of the Ius Constitutionale Commune. In: BOGDANDY, Armin von; MAC-GREGOR, Eduardo F.; ANTONIAZZI, Mariela M.; PIOVESAN, Flávia (ed.). Transnormative Constitutionalism in Latin America: the emergence of a New Ius Commune. Oxford: Oxford University Press, 2017. p. 321-336.

MENEZES, Wagner. Tribunais Internacionais: jurisdição e competência. São Paulo: Saraiva, 2013.

MENEZES, Wagner. Ordem global e transnormatividade. Ijuí: Unijuí, 2005.

PERRONE-MOISÉS, Cláudia. Direito Internacional Penal: imunidades e anistias. São Paulo: Manole, 2012.

PIOVESAN, Flávia. Sistema Interamericano de Direito Humanos: impacto transformador, diálogos jurisdicionais e os desafios da reforma. Revista Direitos Emergentes na Sociedade Global, Santa Maria, RS, v. 3, n. 1, p. 76-101, jan./jun. 2014.

POLIDO, Fabrício B. P. Direito processual internacional e o contencioso internacional privado. Curitiba: Juruá, 2013.

RAMANZINI, Isabela G.; MIRANDA, Geraldo H. R. Em débito com a democracia: panorama latino-americano da justiça de transição na corte interamericana de direitos humanos. Revista Agenda Política, São Carlos, SP, v. 5, n. 3, p. 9-41, 2018.

RAMOS, André de Carvalho. Processo Internacional dos Direitos Humanos. São Paulo: Saraiva, 2012.

RESENDE, Augusto César Leite de. A executividade das sentenças da Corte Interamericana de Direitos Humanos no Brasil. Revista de Direito Internacional, Brasília, v. 10, n. 2, 2013

REZEK, José Francisco. Direito Internacional Público: curso elementar. 15. ed. São Paulo: Saraiva, 2014.

ROUSSET SIRI, Andrés Javier. El concepto de reparación integral en la jurisprudencia de la Corte Interamericana de Derechos Humanos. Revista Internacional de Derechos Humanos, Mendoza, Centro Latinoamericano de Derechos Humanos, ano 1, n. 1, 2011.

SIKKINK, Kathryn. "Ninguém está acima da lei”. Entrevista realizada por Márcia Junges. Revista do Instituto Humanitas Unisinos - IHU, São Leopoldo, n. 269, 18 ago. 2008. 
Disponível em: http://www.ihuonline.unisinos.br/index.php?option=com_content\&view= article\&id=2053\&secao=269. Acesso em: 10 ago. 2019.

SOUZA, Nevitton V. Sistemas de reconhecimento de sentença estrangeira no Brasil. Revista Eletrônica de Direito Processual, Rio de Janeiro, v. 19, n. 3, p. 565-590, 2018.

SPAIN, Anna. Using international dispute resolution to address the compliance question in international law. Georgetown Journal of International Law, Washington, D.C., USA, v. 40, n. 3, 2009.

TEITEL, Ruti G. Genealogia da justiça transicional. In: JUSTIÇA de transição: manual para a América Latina. Brasília: Comissão de Anistia, Ministério da Justiça, 2011. p. 135 170.

VAN ZYL, Paul. Promovendo a justiça transacional em sociedades pós-conflito. In: JUSTIÇA de transição: manual para a América Latina. Brasília: Comissão de Anistia, Ministério da Justiça, 2011. p. 47-71.

VARELLA, Marcelo D. Dificuldades de implementação das decisões da OMC: um estudo de caso a partir do contencioso pneus. Revista Direito GV, São Paulo, v. 10, p. 53-68, 2014.

VASCONCELOS, Raphael Carvalho. Teoria do Estado e a Unidade do Direito Internacional: domesticando o rinoceronte. Belo Horizonte: Arraes, 2016.

WENDPAP, Friedmann; KOLOTELO, Rosane. Direito Internacional. Rio de Janeiro: Elsevier, 2007. 